\title{
Slow breathing reduces sympathoexcitation in COPD
}

\author{
T. Raupach*, F. Bahr*, P. Herrmann\#, L. Luethje*, K. Heusser", G. Hasenfuß*, \\ L. Bernardi ${ }^{+, \$}$ and S. Andreas ${ }^{*,+}$
}

ABSTRACT: Neurohumoral activation has been shown to be present in hypoxic patients with chronic obstructive pulmonary disease (COPD). The aims of the present study were to investigate whether there is sympathetic activation in COPD patients in the absence of hypoxia and whether slow breathing has an impact on sympathoexcitation and baroreflex sensitivity.

Efferent muscle sympathetic nerve activity, blood pressure, cardiac frequency and respiratory movements were continuously measured in 15 COPD patients and 15 healthy control subjects. Baroreflex sensitivity was analysed by autoregressive spectral analysis and the alpha-angle method.

At baseline, sympathetic nerve activity was significantly elevated in COPD patients and baroreflex sensitivity was decreased $\left(5.0 \pm 0.6\right.$ versus $\left.8.9 \pm 0.8 \mathrm{~ms} \cdot \mathrm{mmHg}^{-1}\right)$. Breathing at a rate of 6 breaths $\cdot \mathrm{min}^{-1}$ caused sympathetic activity to drop significantly in COPD patients (from $61.3 \pm 4.6$ to $53.0 \pm 4.3$ bursts per 100 heartbeats) but not in control subjects (39.2 \pm 3.2 versus $37.5 \pm 3.3$ bursts per 100 heartbeats). In both groups, slow breathing significantly enhanced baroreflex sensitivity.

In conclusion, sympathovagal imbalance is present in normoxic chronic obstructive pulmonary disease patients. The possibility of modifying these changes by slow breathing may help to better understand and influence this systemic disease.

KEYWORDS: Baroreflex, chronic obstructive pulmonary disease, slow breathing, sympathetic activity

hronic obstructive pulmonary disease (COPD) is a major cause of death and disability worldwide. In COPD, numerous extrapulmonary abnormalities are present. These include systemic inflammation, cachexia and skeletal muscle dysfunction. Thus, COPD has been called both a muscular [1] and a systemic disease [2]. Recent data demonstrate that hypoxaemic COPD causes marked neurohumoral activation [3,4]. Given the established negative connotations of neurohumoral activation in heart failure and other diseases [5], neurohumoral activation in COPD may well have negative consequences, namely on inflammation, cachexia, skeletal muscle dysfunction and cardiovascular disease [4].

Currently, little is known about the cause of the profound sympathetic activation in patients with COPD. Previous data point to a reduced baroreflex sensitivity in COPD patients [4]. This has been shown by spontaneous variations of blood pressure and cardiac frequency $(f C)$ [6], the phenylephrine test [7] and the Valsalva manoeuvre [8]. Interestingly, impaired baroreflex sensitivity leads to an increase in sympathetic activity through inhibitory afferents [9].

Lung inflation reflexes mediated by pulmonary vagal afferents may alter the baroreflexes and have been shown to govern the within-breath modulation of muscle sympathetic nerve activity as evaluated by microneurography during normal breathing [10]. In patients with chronic heart failure, sympathetic activation is related to a decrease in tidal volume as well as an attenuated sympatho-inhibitory effect of the lung inflation reflex [11]. Conversely, slow breathing increases arterial baroreflex sensitivity and improves exercise capacity in these patients $[9,12]$. Thus, it seems possible that slow breathing impacts on baroreflex sensitivity and sympathetic outflow in COPD.

Sympathetic activity is accurately quantified by microneurography. Previous investigations have

\section{AFFILIATIONS}

*Depts of Cardiology and

Pneumology

${ }^{\#}$ Anaesthesiology II and Intensive Care, Georg-August University Göttingen, Göttingen,

'Dept of Clinical Pharmacology,

Hanover Medical School, Hanover, and ${ }^{f}$ Specialist Lung Clinic Immenhausen, Immenhausen, Germany.

+Dept of Internal Medicine, University of Pavia, and

${ }^{\S}$ Istituto di Ricovero e Cura a Carattere Scientifico (IRCCS) San Matteo, Pavia, Italy.

CORRESPONDENCE

S. Andreas

Lungenfachklinik Immenhausen

Robert-Koch-Strasse 3

D-34376 Immenhausen

Germany

Fax: 495673501101

E-mail: sandreas@

lungenfachklinik-immenhausen.de

Received:

August 212007

Accepted after revision:

March 102008

SUPPORT STATEMENT

The present study was funded by the

Deutsche Forschungsgemeinschaft

(German Research Foundation;

Bonn, Germany), project number

An 260/6-1.

STATEMENT OF INTEREST

Statements of interest for T. Raupach

and $\mathrm{S}$. Andreas can be found at

www.erj.ersjournals.com/misc

statements.shtm 
demonstrated that muscle sympathetic nerve activity (MSNA) reflects short-term changes in sympathetic activity, is highly reproducible and correlates closely with cardiac norepinephrine spillover [13]. Therefore, the aims of the present study were to evaluate: 1) whether sympathetic over activity is present even in normoxic COPD patients; and 2) whether slow breathing has an impact on sympathetic tone and baroreflex sensitivity in these patients.

\section{METHODS}

\section{Subjects}

Nonsmoking, normoxic individuals aged 30-80 yrs with stable sinus rhythm and a diagnosis of COPD with a forced expiratory volume in one second $\leqslant 60 \%$ predicted, who were on medical treatment according to the Global Initiative for Chronic Obstructive Lung Disease guidelines [14], were eligible for participation in the study. General exclusion criteria were as follows: hypercapnia on arterial blood gas analysis, with arterial carbon dioxide tension $\left(\mathrm{Pa}_{1} \mathrm{CO}_{2}\right)>6.0 \mathrm{kPa}$ (45 mmHg); recent ( $<3$ months) history of COPD exacerbation; unstable heart disease; polyneuropathy; systemic treatment with sympathomimetic drugs; or diagnosis of a disorder known to be accompanied by sympathetic activation.

Healthy, nonsmoking volunteers were recruited from the general public via advertisements and matched by sex, age, weight and smoking status to the COPD patients. They did not have any acute or chronic disease and were not on any regular medication.

Patients were asked not to take any diuretic drugs before the measurements were completed. The study was approved by the local ethics committee (University of Göttingen, Göttingen, Germany). Informed written consent was obtained from all patients and control subjects.

\section{Microneurography and measurement of respiration and transcutaneous blood gases}

Sympathetic nerve activity was measured using microneurographic recordings of efferent muscle sympathetic nerve activity in the peroneal nerve of the right leg, as described previously [15]. Respiratory rate and tidal volume were approximated by calibrated respiratory inductive plethysmography (Respitrace Systems; Ambulatory Monitoring Inc., Ardsley, NY, USA), as described previously [3].

In a set of additional experiments in seven COPD patients, arterial oxygen saturation $\left(\mathrm{Sa}_{\mathrm{a}} \mathrm{O}_{2}\right)$ and transcutaneous carbon dioxide tension $\left(\mathrm{Ptc}_{\mathrm{tc}} \mathrm{CO}_{2}\right)$ were assessed using fingertip pulse oximetry and the Tosca ${ }^{\circledR}$ device (Linde Medical Sensors, Basel, Switzerland).

\section{Blood pressure, fc and baroreflex}

Blood pressure was measured automatically and noninvasively with the Portapres ${ }^{\circledR}$ device (Finapres Medical Systems, Amsterdam, the Netherlands). $f C$ was derived from a continuous ECG recording.

Spontanous baroreflex sensitivity was measured by spectral analysis using the alpha-angle method, as described previously $[9,16]$. Briefly, the gain of the arterial baroreflex was obtained by dividing the amount of spontaneous fluctuation in the R-R interval of the ECG by the spontaneous fluctuations of systolic blood pressure at the same frequency. This approach gives results closely correlated with those obtained using the Oxford phenylephrine test and has the advantage of allowing the baroreflexes to be evaluated with no need for external stimulation over a longer time period [17]. Additional detail of the methods is provided in the online supplementary material.

\section{Protocol}

Experiments were conducted in the morning. Subjects were in a supine position with a $30^{\circ}$ elevation of the chest during experiments. After obtaining a satisfactory nerve signal, baseline measurements were performed for $20 \mathrm{~min}$, then respiration was regularised by instructions from the investigators. Subjects were instructed to breathe at a respiratory rate of 15 breath$\mathrm{s} \cdot \mathrm{min}^{-1}$ for $4 \mathrm{~min}$, followed by another $4 \mathrm{~min}$ respiration at 6 breaths $\cdot \min ^{-1}$ (3 s inspiration, $7 \mathrm{~s}$ expiration) [12]. Breathing rates of 6 breaths $\cdot \mathrm{min}^{-1}$ were achieved even in patients with severe COPD, by a training period with visual feedback.

\section{Data analysis}

Data recording and analysis was performed using the Modular Intensive Care Data Acquisition System developed by $P$. Herrmann in cooperation with X.P. Nguyen at the Mannheim Biomedical Engineering Laboratories (Institut für Biomedizinische Technik, Hochschule Mannheim, Mannheim, Germany). Sympathetic bursts were quantified manually and independently by two observers (T. Raupach and F. Bahr) blinded to both subject and intervention. In the Dept of Cardiology and Pneumology, Georg-August University Göttingen (Göttingen, Germany), the intra-observer variation in identifying bursts was $5 \%$, and the interobserver variation was $11 \%$ [3]. MSNA was computed in bursts per minute and bursts per 100 heartbeats, both of which yielded similar results. Thus, data are presented only in bursts per 100 heartbeats. All data in the text and tables are presented as mean \pm SEM. Statistical significance was accepted at a value of $p \leqslant 0.05$. Repeatedmeasures ANOVA, with time as the within-groups factor and the time by treatment interaction as the indicator of differential changes in both study groups, was used to analyse the effects of slow breathing.

\section{RESULTS}

\section{Baseline characteristics}

A total of 20 COPD patients and 29 control subjects were included in the study. All the COPD patients used long-acting inhaled $\beta_{2}$-agonists, eight additionally used inhaled tiotropium, and three used inhaled glucocorticosteroids. Noninvasive ventilation was not used by any patient. Valid MSNA data could be obtained in 15 COPD patients and 15 healthy control subjects matched in a 1:1 fashion (an exemplary display of the MSNA signal is given in figure S1 in the online supplementary material). The baseline characteristics of these participants are summarised in table 1.

The $\mathrm{Pa}, \mathrm{CO}_{2}$ and $f C$ were significantly higher in the COPD patients than the controls. There was no significant difference between the two groups regarding plasma concentrations of adrenaline and noradrenaline.

Under resting conditions, MSNA was significantly higher in COPD patients than in control subjects $(59.0 \pm 4.5$ versus $40.3 \pm 2.6$ bursts per 100 heartbeats; $\mathrm{p}<0.001$; fig. 1 ). 


\section{TABLE 1 Baseline characteristics of study subjects}

\begin{tabular}{|c|c|c|c|}
\hline & COPD & Controls & p-value \\
\hline Subjects $n$ & 15 & 15 & \\
\hline Age yrs & $60.9 \pm 1.4$ & $60.7 \pm 1.4$ & 0.919 \\
\hline Height $\mathbf{m}$ & $1.71 \pm 0.02$ & $1.75 \pm 0.03$ & 0.254 \\
\hline Weight kg & $78.7 \pm 3.1$ & $81.1 \pm 2.6$ & 0.553 \\
\hline BMI $\mathbf{k g} \cdot \mathbf{m}^{-2}$ & $27.0 \pm 1.1$ & $26.5 \pm 0.9$ & 0.735 \\
\hline FEV $1 \%$ pred & $46.4 \pm 3.7$ & $101.4 \pm 2.5$ & $<0.001$ \\
\hline $\mathrm{FEV}_{1} / \mathrm{VC}$ & $53.5 \pm 2.8$ & $79.0 \pm 1.0$ & $<0.001$ \\
\hline VC \% pred & $63.1 \pm 4.1$ & $95.2 \pm 3.0$ & $<0.001$ \\
\hline $\mathrm{RV} / \mathrm{TLC}$ & $47.3 \pm 3.2$ & $35.1 \pm 2.9$ & 0.017 \\
\hline$P 0.1 \mathrm{kPa}$ & $0.39 \pm 0.05$ & $0.11 \pm 0.03$ & $<0.001$ \\
\hline $\mathrm{PI}, \max \mathrm{kPa}$ & $5.64 \pm 0.64$ & $8.41 \pm 0.95$ & 0.026 \\
\hline Arterial pH & $7.38 \pm 0.01$ & $7.38 \pm 0.01$ & 0.797 \\
\hline $\mathrm{Pa}, \mathrm{CO}_{2} \mathrm{mmHg}$ & $42.0 \pm 0.91$ & $39.1 \pm 1.05$ & 0.048 \\
\hline $\mathrm{Pa}, \mathrm{O}_{2} \mathrm{mmHg}$ & $76.5 \pm 2.3$ & $82.5 \pm 2.8$ & 0.112 \\
\hline $\mathrm{Sa}, \mathrm{O}_{2} \%$ & $94.5 \pm 0.5$ & $95.3 \pm 0.5$ & 0.284 \\
\hline Systolic blood pressure $\mathrm{mmHg}$ & $127.5 \pm 8.2$ & $135.6 \pm 7.6$ & 0.476 \\
\hline Diastolic blood pressure $\mathrm{mmHg}$ & $62.8 \pm 3.5$ & $68.7 \pm 3.4$ & 0.244 \\
\hline$f c$ beats $\cdot \min ^{-1}$ & $79.0 \pm 3.2$ & $69.7 \pm 1.7$ & 0.016 \\
\hline Respiratory rate breaths $\cdot \min ^{-1}$ & $16.2 \pm 1.1$ & $16.9 \pm 0.7$ & 0.603 \\
\hline Adrenaline $\mathbf{n g} \cdot \mathrm{L}^{-1}$ & $26.6 \pm 3.9$ & $27.9 \pm 4.7$ & 0.844 \\
\hline Noradrenaline $\mathrm{ng} \cdot \mathrm{L}^{-1}$ & $222.6 \pm 16.0$ & $218.0 \pm 22.9$ & 0.869 \\
\hline
\end{tabular}

Data are presented as mean \pm SEM, unless otherwise stated. COPD: chronic obstructive pulmonary disease; BMI: body mass index; FEV 1 : forced expiratory volume in one second; \% pred: \% predicted; VC: vital capacity; RV: residual volume; TLC: total lung capacity; P0.1: mouth occlusion pressure at $0.1 \mathrm{~s}$; $\mathrm{Pl}$,max: maximal inspiratory pressure; $\mathrm{Pa}_{\mathrm{a}} \mathrm{CO}_{2}$ : arterial carbon dioxide tension; $\mathrm{Pa}_{1} \mathrm{O}_{2}$ : arterial oxygen tension; $\mathrm{Sa}_{\mathrm{O}_{2}}$ : arterial oxygen saturation; $\mathrm{fC}$ : cardiac frequency. $1 \mathrm{mmHg}=0.133 \mathrm{kPa}$.

Owing to difficulties in obtaining valid blood pressure signals and the presence of ectopic heartbeats in some of the tracings, reliable baroreflex data were only available for 12 COPD patients.

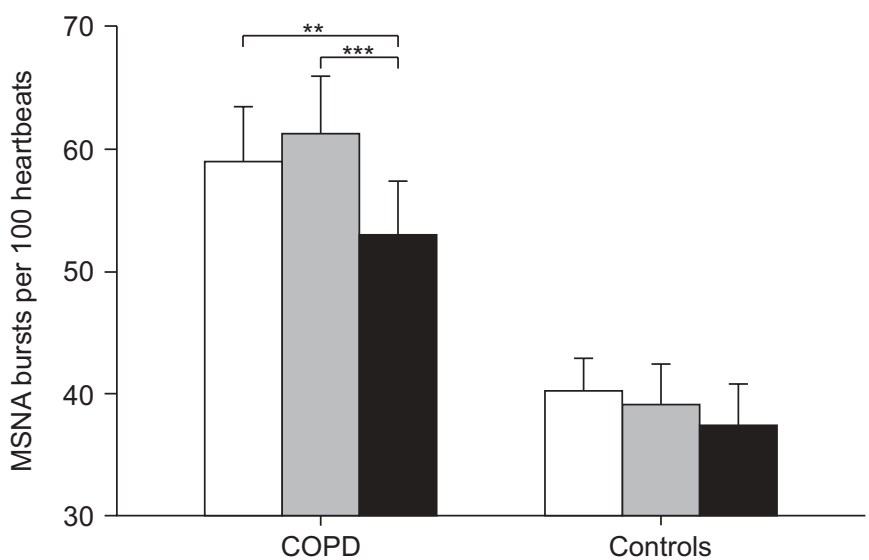

FIGURE 1. Effect of regular and slow breathing on muscle sympathetic nerve activity (MSNA) in 15 chronic obstructive pulmonary disease (COPD) patients and 15 healthy control subjects. $\square$ : spontaneous breathing; $\square$ : respiratory rate 15 breaths $\cdot \mathrm{min}^{-1} ; \mathbf{\square}$ : respiratory rate 6 breaths $\cdot \mathrm{min}^{-1}$. ${ }^{* *}: \mathrm{p}<0.01$; $* \star *: p<0.001$
These were compared with data from the 12 matched control subjects. At baseline, alpha-angle values in controls exceeded those in COPD patients $\left(9.3 \pm 1.1\right.$ versus $5.0 \pm 0.6 \mathrm{~ms} \cdot \mathrm{mmHg}^{-1}$; $\mathrm{p}=0.009$; fig. 2).

\section{Regularisation of respiratory rate}

Upon regularisation of the breathing pattern and standardisation of the respiratory rate to 15 breaths $\cdot \mathrm{min}^{-1}$, the $f C$ increased significantly in control subjects (from $69.7 \pm 1.7$ to $71.5 \pm 1.7$ beats $\cdot \min ^{-1} ; p=0.038$ ). No significant change in systolic or diastolic blood pressure, or sympathetic activity (corrected for $f C)$, was observed in either group. At a breathing rate of 15 breaths $\cdot \min ^{-1}$, baroreflex sensitivity was significantly higher in control subjects than in COPD patients $(7.8 \pm 0.9$ versus $\left.3.3 \pm 0.6 \mathrm{~ms} \cdot \mathrm{mmHg}^{-1} ; \mathrm{p}<0.001\right)$.

When switching from baseline to a respiratory rate of 15 breath$\mathrm{s} \cdot \mathrm{min}^{-1}$, the minute ventilation increased by $68.3 \pm 15.4 \%$ in COPD patients and $93.5 \pm 25.0 \%$ in healthy controls. Upon reduction of the respiratory rate from 15 to 6 breaths $\cdot \mathrm{min}^{-1}$, the minute ventilation decreased significantly in both groups (by $30.5 \pm 4.5 \%$ in COPD patients and by $32.6 \pm 5.9 \%$ in controls). Additional experiments in seven COPD patients revealed that the $\mathrm{Sa}, \mathrm{O}_{2}$ increased significantly upon regularising the breathing rate to 15 breaths $\cdot \mathrm{min}^{-1}$ (from $94.0 \pm 0.9$ to $96.0 \pm 0.8 \% ; \mathrm{p}=0.017$ ) and 6 breaths $\cdot \mathrm{min}^{-1}$ (from $96.0 \pm 0.8$ to $97.0 \pm 0.5 \% ; \mathrm{p}=0.038$ ). The $P \mathrm{tc}, \mathrm{CO}_{2}$ decreased from $5.4 \pm 0.09 \mathrm{kPa}(40.7 \pm 0.7 \mathrm{mmHg})$ to $4.5 \pm 0.11 \mathrm{kPa}(34.2 \pm 0.8 \mathrm{mmHg} ; \mathrm{p}=0.027)$ when the breathing rate was set to 15 breaths $\cdot \mathrm{min}^{-1}$. There was a further decrease to $4.2 \pm 0.21 \mathrm{kPa}(31.5 \pm 1.6 \mathrm{mmHg})$ following the adoption of slow breathing $(\mathrm{p}=0.068)$.

\section{Effects of slow breathing on sympathetic activity and baroreflex sensitivity}

Slow breathing ( 6 breaths $\cdot \mathrm{min}^{-1}$ ), as opposed to breathing at a respiratory rate of 15 breaths $\cdot \mathrm{min}^{-1}$, led to a significant decrease in MSNA in 15 COPD patients (from $61.3 \pm 4.6$ to $53.0 \pm 4.3$ bursts per 100 heartbeats; $\mathrm{p}<0.001$ ) but not in the 15 healthy controls $(39.2 \pm 3.2$ versus $37.5 \pm 3.3$ bursts per 100 heartbeats; $p=0.308$;

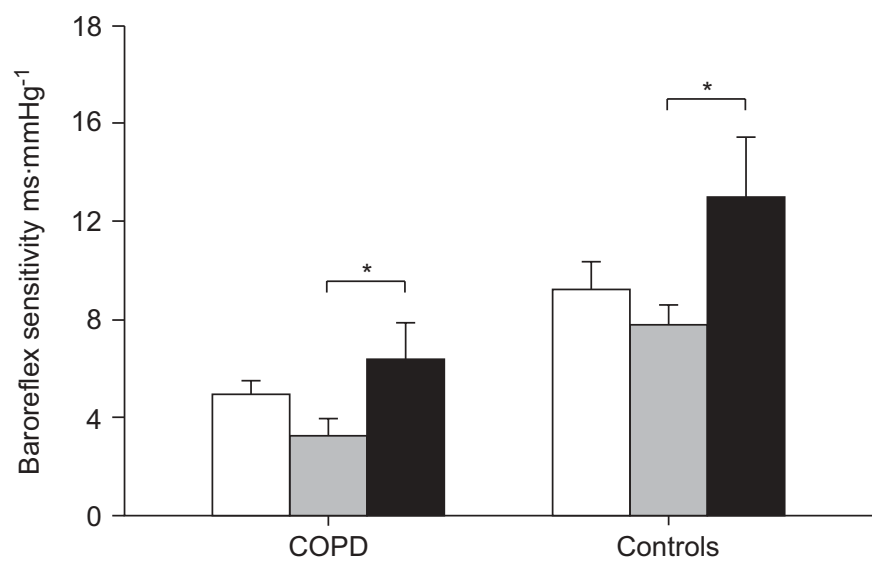

FIGURE 2. Effect of regular and slow breathing on baroreflex sensitivity in 12 chronic obstructive pulmonary disease (COPD) patients and 12 healthy contro subjects. $\square$ : spontaneous breathing; $\square$ : respiratory rate 15 breaths $\cdot \mathrm{min}^{-1}$; ש: respiratory rate 6 breaths $\cdot \min ^{-1} . *: p<0.05$. 
fig. 3). Repeated-measures ANOVA revealed a significant between-groups difference regarding the effect of slow breathing on sympathetic activity (for interaction, $\mathrm{p}=0.01$ ). Comparing MSNA at a respiratory rate of 6 breaths $\cdot \mathrm{min}^{-1}$ with that at baseline revealed similar results (fig. 1). Slow breathing, compared with breathing at 15 breaths $\cdot \mathrm{min}^{-1}$ or baseline conditions, did not influence $f C$ or systolic or diastolic blood pressure in either group (see tables S1 and S2 in the online supplementary material).

The effects of slow breathing on baroreflex sensitivity are summarised in figure 2 . In both groups, a significant increase in alpha-angle values was only observed for slow breathing when compared with breathing at a rate of 15 breaths $\cdot \mathrm{min}^{-1}$ (COPD: $5.2 \pm 1.1$ versus $3.3 \pm 0.6 \mathrm{~ms} \cdot \mathrm{mmHg}^{-1}$, respectively, $\mathrm{p}=0.04$; controls: $13.0 \pm 2.5$ versus $7.8 \pm 0.9 \mathrm{~ms} \cdot \mathrm{mmHg}^{-1}$, respectively, $\mathrm{p}=0.042$ ). Due to this similar trend in both groups towards higher baroreflex sensitivity, no significant interaction effect was detected by ANOVA for either comparison. Changes in MSNA induced by slow breathing did not correlate significantly with baseline arterial oxygen tension or changes in baroreflex sensitivity (data not shown).

\section{DISCUSSION}

\section{Main findings}

The present data, showing direct evidence of sympathetic over activation in patients with normoxic COPD, extend previous observations in hypoxaemic lung disease [3]. Slow breathing acutely reduced sympathetic activity and tended to increase baroreflex sensitivity in COPD patients, indicating that slow breathing positively modulated the sympathovagal balance, which was markedly altered in these patients.

\section{Sympathovagal balance in COPD}

In patients with COPD, sympathetic activity was nearly twice as high as in a matched control group of healthy individuals. Importantly, hypoxia was not present in any subject at the time of study. This extends previous findings in hypoxic patients [3] to COPD patients without hypoxia.

The current findings indicate that, in COPD, sympathetic activation and vagal withdrawal is at least as pronounced as in other chronic conditions, such as severe heart failure [9, 18]. The data are also in line with reports of long-standing $f C$ elevation in patients with COPD [4]. This is further supported by the finding of a significantly decreased baroreflex sensitivity in COPD patients that is in keeping with an earlier study using the phenylephrine test in order to determine baroreceptor sensitivity [7].

It is highly unlikely that inhaled $\beta_{2}$-agonists explain the findings, since striking sympathoexitation was also found in patients with restrictive lung disease without any $\beta_{2}$-agonist medication [3]. Furthermore, intravenous adrenaline $\left(0.3 \mathrm{nmol} \cdot \mathrm{kg}^{-1} \cdot \mathrm{min}^{-1}\right)$ caused striking tachycardia but only a mild increase in MSNA from 20 to 23 bursts $\cdot \mathrm{min}^{-1}$ [19].

Although slow breathing had a clear effect on the autonomic nervous system in COPD, it did not lead to a normalisation of baroreflexes and sympathetic activity in the current patients. The present data do not prove a causal link between altered baroreflexes and heightened sympathetic activity in COPD. Instead, it is reasonable to suggest that a number of synergistic mechanisms, including chemo-, ergo- and lung inflation reflexes, contribute to sympathetic activation in COPD $[3,4]$. a)

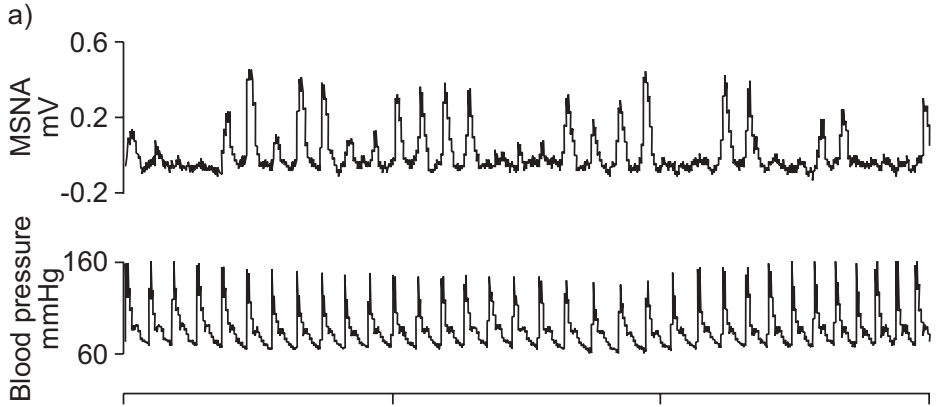

c)

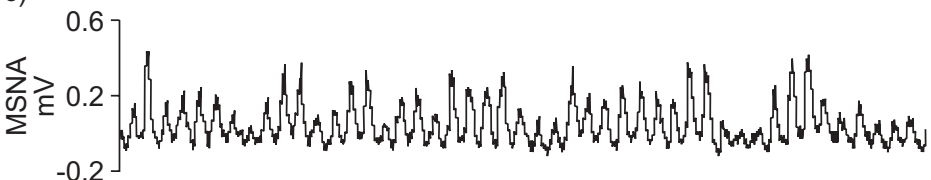
$-0.2$

号

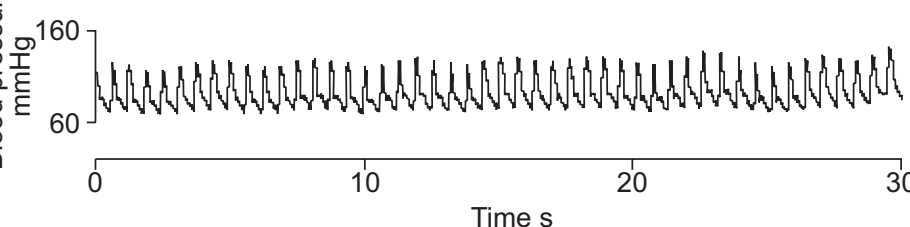

b)

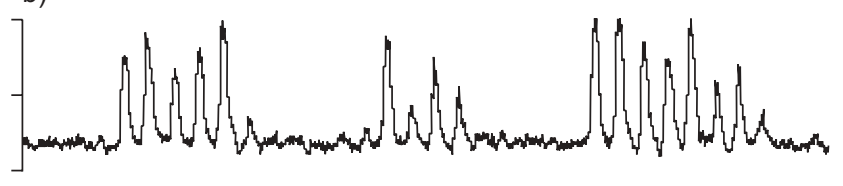

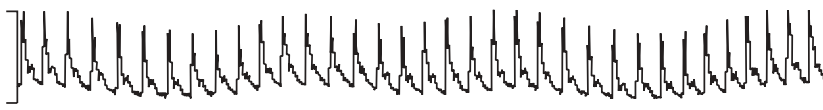

d)

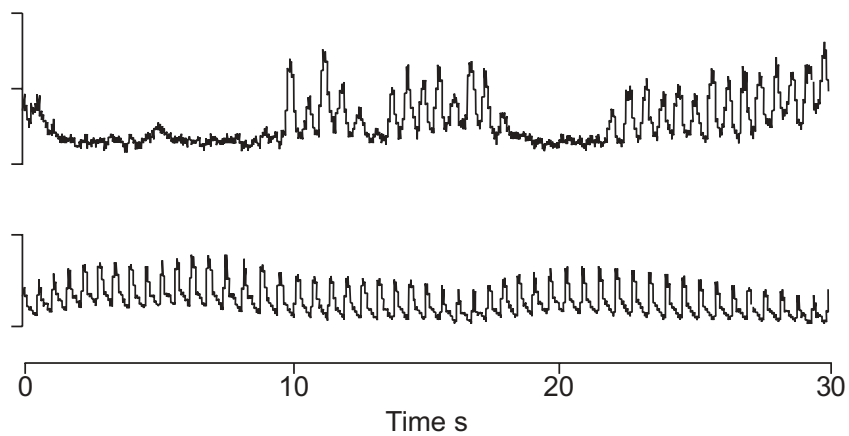

FIGURE 3. Exemplary display of a respiratory rate of 15 breaths $\cdot \mathrm{min}^{-1}$ (a and c), compared with the effect of slow breathing (6 breaths.min ${ }^{-1} ; b$ and d), on muscle sympathetic nerve activity (MSNA; integrated data) and blood pressure in a healthy control subject ( $a$ and $b$ ) and a chronic obstructive pulmonary disease patient (c and d). 


\section{Effects of regular and slow breathing}

There are several possible explanations for the effect of slow breathing on sympathoexcitation. Slow breathing may reduce sympathetic activity by enhancing central inhibitory rhythms [20] and, conversely, have an impact on baroreflex sensitivity. Furthermore, activation of the Hering-Breuer reflex due to an increase in tidal volume during slow breathing [21] reduces chemoreflex sensitivity and might, therefore, ameliorate baroreflex function [11, 21, 22]. Additionally, reducing the respiratory rate to 6 breaths $\cdot \mathrm{min}^{-1}$ entrains $\mathrm{R}-\mathrm{R}$ interval fluctuations, causing a merging with the respiratory cycle as well as a considerable increase in amplitude relative to blood pressure changes. This may lead to enhanced baroreflex efficiency [9].

Changes in blood gases might contribute to, but are unlikely to fully explain, the observed changes in MSNA and baroreflex sensitivity, since the main increase in $\mathrm{Sa}_{2} \mathrm{O}_{2}$, as well as the main decrease in $P_{\mathrm{tc}}, \mathrm{CO}_{2}$, were observed upon switching from baseline conditions to a respiratory rate of 15 breaths $\cdot \mathrm{min}^{-1}$. During this part of the protocol, no significant changes in MSNA and baroreflex sensitivity were observed. In fact, there was even a small but insignificant increase in MSNA with breathing at 15 breaths $\cdot \mathrm{min}^{-1}$. Thus, $\mathrm{Sa}_{2} \mathrm{O}_{2}$ increased and $\mathrm{Ptc}_{\mathrm{tc}} \mathrm{CO}_{2}$ decreased significantly upon regularisation of breathing (to 15 breaths $\cdot \mathrm{min}^{-1}$ ), but MSNA did not decrease. Changes in blood gases detected upon slow breathing were minor and only partly significant.

The effect of slow breathing on MSNA was only present in COPD patients. This might be explained by the diverse sympathovagal balance in the two groups. Slow breathing is, thus, more likely to reduce MSNA in an activated system compared with a resting system exhibiting basal nerve traffic. Nevertheless, slow breathing has the potential to impact on baroreflex sensitivity in patients and controls alike. Previous studies in patients with chronic heart failure or arterial hypertension found an effect similar to that observed in the present study $[9,23]$.

The impact of slow breathing on MSNA seen in COPD might be attributed to the centrally mediated regularisation of the respiratory pattern. However, no significant changes in MSNA were seen upon changing the respiratory rate from baseline (16-17 breaths $\cdot \mathrm{min}^{-1}$ ) to 15 breaths $\cdot \mathrm{min}^{-1}$, which also regularised the respiratory cycle.

\section{Interaction of cardiovascular and respiratory control}

Taking the present study together with previous studies $[9,12$, 23], it seems that slow breathing induces a generalised attenuation of excitatory pathways regulating respiratory and cardiovascular systems. In this context, mutual interference of these systems is likely to occur in response to alterations affecting only one part, since both systems share similar control mechanisms [24]. It has been shown previously that slow breathing reduces chemoreflex activation due to hypoxia and hypercapnia in healthy subjects [22]. In the presence of heart failure, a condition known to induce sympathetic activation, slow breathing was associated with a reduction in sympathetic activation as well as a strengthening of inhibitory pathways, such as the arterial baroreflex $[9,21]$. In addition, this intervention induced an increase in baroreflex and even in exercise capacity $[9,12]$.
The insight into sympathovagal imbalance as a pathophysiological phenomenon in COPD, in concert with the potential to at least partly counteract these changes by slow breathing, might pave the way for new treatment strategies that could include multidirectional interventions aimed at the numerous dysfunctions seen in COPD.

Interestingly, pursed-lip breathing reduces respiratory rate and breathlessness in COPD patients at rest and during exercise [25, 26]. Physiotherapy has long been used as an adjunct to pharmacological COPD treatment. The present study provides evidence for a possible underlying cause of the beneficial effects of this kind of treatment (which includes training in slow breathing).

\section{Study limitations}

Although clear short-term effects of slow breathing were observed, it remains to be assessed whether longer term practice will lead to stable modifications of cardiovascular and respiratory control.

For unobtrusive registration of the sympathovagal balance, the current authors decided not to evaluate ventilation by mouthpiece. Instead, respiratory inductive plethysmography was used. Although this is the most widely accepted method for noninvasive respiratory measurements, there is as much as $10 \%$ deviation between plethysmography and spirometry in patients with lung disease, even when using the least-squares calibration technique [27]. Conversely, highly reliable methods to determine minute ventilation would involve the use of a mouthpiece or a face mask, possibly giving rise to discomfort, alterations in breathing pattern and an artefactual increase in ventilation [28]

Spontaneous baroreflex sensitivity was assessed in the present study. Although more invasive methods such as the phenylephrin method are available, they are also likely to impact on other variables relevant for the question under study. Thus, the less intrusive alpha-angle method was preferred, since it is an accepted method for measuring baroreflex sensitivity [29].

Due to electrical interference of oximetry devices with the MSNA signal, $\mathrm{Sa}, \mathrm{O}_{2}$ and $\mathrm{Ptc}_{\mathrm{tc}} \mathrm{CO}_{2}$ were only evaluated in a second set of experiments, using the same protocol but without registration of MSNA, in a limited number of patients. Furthermore, it was not possible to control for the effects of pursed-lip breathing. Studies using strict methodology to evaluate haemodynamics, blood gases and ventilation will be necessary in order to better understand the complex effects of slow breathing and pursed-lip breathing.

\section{Conclusion}

In summary, patients with chronic obstructive pulmonary disease showed sympathetic excitation and depression of the baroreflex. Slow breathing counteracted these changes. Given the negative consequences of sympathetic activation and vagal withdrawal, modulation of the sympathovagal balance by slow breathing might have the potential to impact on systemic effects in chronic obstructive pulmonary disease patients.

\section{REFERENCES}

1 Reid MB. COPD as a muscle disease. Am J Respir Crit Care Med 2001; 164: 1101-1102. 
2 Wouters EF. Chronic obstructive pulmonary disease. 5: systemic effects of COPD. Thorax 2002; 57: 1067-1070.

3 Heindl S, Lehnert M, Criée CP, Hasenfuß G, Andreas S. Marked sympathetic activation in patients with chronic respiratory failure. Am J Respir Crit Care Med 2001; 164: 597-601.

4 Andreas S, Anker SD, Scanlon PD, Somers VK. Neurohumoral activation as a link to systemic manifestations of chronic lung disease. Chest 2005; 128: 3618-3624.

5 Anker SD, Coats AJ. Cardiac cachexia: a syndrome with impaired survival and immune and neuroendocrine activation. Chest 1999; 115: 836-847.

6 Bartels MN, Gonzalez JM, Kim W, De Meersman RE. Oxygen supplementation and cardiac-autonomic modulation in COPD. Chest 2000; 118: 691-696.

7 Patakas D, Louridas G, Kakavelas E. Reduced baroreceptor sensitivity in patients with chronic obstructive pulmonary disease. Thorax 1982; 37: 292-295.

8 Hjalmarsen A, Aasebø U, Aleksandersen G, Jorde R. Cardiovascular responses to tests for autonomic dysfunction in patients with chronic obstructive pulmonary disease with and without continuous long-term oxygen therapy. J Auton Nerv Syst 1996; 60: 169-174.

9 Bernardi L, Porta C, Spicuzza L, et al. Slow breathing increases arterial baroreflex sensitivity in patients with chronic heart failure. Circulation 2002; 105: 143-145.

10 Dempsey JA, Sheel AW, St Croix CM, Morgan BJ. Respiratory influences on sympathetic vasomotor outflow in humans. Respir Physiol Neurobiol 2002; 130: 3-20.

11 Goso Y, Asanoi H, Ishise H, et al. Respiratory modulation of muscle sympathetic nerve activity in patients with chronic heart failure. Circulation 2001; 104: 418-423.

12 Bernardi L, Spadacini G, Bellwon J, Hajric R, Roskamm H, Frey AW. Effect of breathing rate on oxygen saturation and exercise performance in chronic heart failure. Lancet 1998; 351: 1308-1311.

13 Wallin BG, Esler M, Dorward $\mathrm{P}$, et al. Simultaneous measurements of cardiac noradrenaline spillover and sympathetic outflow to skeletal muscle in humans. J Physiol 1992; 453: 45-58.

14 Pauwels RA, Buist AS, Calverley PM, Jenkins CR, Hurd SS, GOLD Scientific Committee. Global strategy for the diagnosis, management, and prevention of chronic obstructive pulmonary disease. NHLBI/WHO Global Initiative for Chronic Obstructive Lung Disease (GOLD) Workshop summary. Am J Respir Crit Care Med 2001; 163: 1256-1276.

15 Heindl S, Dodt C, Krahwinkel M, Hasenfuß G, Andreas S. Short term effect of continuous positive airway pressure on muscle sympathetic nerve activity in patients with chronic heart failure. Heart 2001; 85: 185-190.
16 Malliani A, Pagani M, Lombardi F, Cerutti S. Cardiovascular neural regulation explored in the frequency domain. Circulation 1991; 84: 482-492.

17 Rudas L, Crossman AA, Morillo CA, et al. Human sympathetic and vagal baroreflex responses to sequential nitroprusside and phenylephrine. Am J Physiol 1999; 276: H1691-H1698.

18 Andreas S, Reiter H, Lüthje L, et al. Differential effects of theophylline on sympathetic excitation, hemodynamics, and breathing in congestive heart failure. Circulation 2004; 110: 2157-2162.

19 Persson B, Andersson OK, Hjemdahl P, Wysocki M, Agerwall S, Wallin G. Adrenaline infusion in man increases muscle sympathetic nerve activity and noradrenaline overflow to plasma. J Hypertens 1989; 7: 747-756.

20 Naughton MT, Floras JS, Rahman MA, Jamal M, Bradley TD. Respiratory correlates of muscle sympathetic nerve activity in heart failure. Clin Sci (Lond) 1998; 95: 277-285.

21 Bernardi L, Gabutti A, Porta C, Spicuzza L. Slow breathing reduces chemoreflex response to hypoxia and hypercapnia, and increases baroreflex sensitivity. J Hypertens 2001; 19: 2221-2229.

22 Spicuzza L, Gabutti A, Porta C, Montano N, Bernardi L. Yoga and chemoreflex response to hypoxia and hypercapnia. Lancet 2000; 356: 1495-1496.

23 Joseph CN, Porta C, Casucci G, et al. Slow breathing improves arterial baroreflex sensitivity and decreases blood pressure in essential hypertension. Hypertension 2005; 46: 714-718.

24 Derchak PA, Sheel AW, Morgan BJ, Dempsey JA. Effects of expiratory muscle work on muscle sympathetic nerve activity. J Appl Physiol 2002; 92: 1539-1552.

25 Bianchi R, Gigliotti F, Romagnoli I, et al. Chest wall kinematics and breathlessness during pursed-lip breathing in patients with COPD. Chest 2004; 125: 459-465.

26 Spahija J, de Marchie M, Grassino A. Effects of imposed pursed-lips breathing on respiratory mechanics and dyspnea at rest and during exercise in COPD. Chest 2005; 128: 640-650.

27 Tobin MJ, Jenouri G, Lind B, Watson H, Schneider A, Sackner MA. Validation of respiratory inductive plethysmography in patients with pulmonary disease. Chest 1983; 83: 615-620.

28 Askanazi J, Silverberg PA, Foster RJ, Hyman AI, MilicEmili J, Kinney JM. Effects of respiratory apparatus on breathing pattern. J Appl Physiol 1980; 48: 577-580.

29 Davies LC, Francis D, Jurák P, Kára T, Piepoli M, Coats AJ. Reproducibility of methods for assessing baroreflex sensitivity in normal controls and in patients with chronic heart failure. Clin Sci (Lond) 1999; 97: 515-522. 